\title{
Pattern of Admission of Common Medical Diseases During the Year 2015 to Sulaimani Teaching Hospital Khalid Ali Hassan (MBChB,HDIM) ${ }^{1}$
}

\begin{abstract}
Background:The main reasons for admission to the medical wards in high -income countries are non communicable diseases While communicable diseases are the main reasons for admission to the medical wards in low and middle income countries. However, the reasons for admission are changing from communicable diseases to non-communicable diseases in some low and middle income countries.

Objective: To assess the frequency and the pattern of medical diseases for patients admitted to the medical wards of Sulaimani Teaching Hospital during the year 2015. Patients and Methods: A retrospective study was conducted in Sulaimani Teaching Hospital for 26700 medical records of the patients who were admitted to the medical wards during the year 2015 (started from 1st January to 31th December), All the patients that had been admitted to the medical wards of Sulaimani Teaching Hospital during the year 2015 were referred from medical emergency department and outpatient clinics in addition to the private clinics. The data were obtained from medical records of the patients in statistic unit of the hospital. The variables involved in the study included age of the patients, gender, residency and final diagnosis.

Results: This study included 26700 patients that have been admitted to Sulaimani Teaching Hospital, $14853(55.62 \%)$ were females and 11847(44.38\%) were males. Most admitted age groups were between 51- 60 years $(18.16 \%)$ followed by $61-70$ years $(17.52 \%), 71$ years and more $(16.58 \%)$, 41-50 years $(14.92 \%), 21-30$ years $(13.36 \%), 31-40$ years $(12.79 \%)$ while the least admitted age group was less than 20 years $(6.67 \%), 62.85 \%$ of the patients were from urban areas and $37.15 \%$ were from rural areas. Gastroenteritis was the most common medical illness $(6.45 \%)$, followed by CerebroVascular Accidant CVA (6.27\%), Chronic Obstructive Pulmonary Disease COPD (5.52\%), Hypertension HT (4.25\%),Diabetes Mellitus DM (4.23\%),Bronchial Asthma (2.80\%),Heart Failure HF (2.60\%),Pneumonia (2.28\%),Urinary Tract Infection UTI(1,92\%), Anaemia (1.86\%) ,Miscellaneous diseases $(35.78 \%)$ and finally the diseases that not diagnosed $(26.04 \%)$. The highest number of admissions were in Summer comprising $(26.96 \%)$ of all admissions followed by in Autumn $(25,10 \%)$ then in Spring $(24,34 \%)$ and the lowest in Winter comprising $(23.60 \%)$ of all admissions. The highest number of admission were in July comprising $(9.42 \%)$ of all admissions followed by June $(8.87 \%)$, October(8.72\%),August (8.68\%),May(8.43\%),September(8.36\%(

December(8.30\%),April(8.15\%),November(8.02\%),January(7.97\%),March(7.76\%) and the lowest in February $(7.32 \%)$ of all admissions.

Conclusion: The commonest age group for admission is 51-60 year. Admission rate more common in females than in males and it is more common in Summer than in Winter. There is a seasonal variation in the hospital admission. The non-communicable diseases represent the main causes for medical admission than the communicable diseases.

Keywords: Patterns, Admission, Medical illness.

Corresponding Author: dr.khalidalihassan@gmail.com

Received: $18^{\text {th }}$ November 2018

Accepted: $17^{\text {th }}$ February 2019

https://doi.org/10.26505/DJM
\end{abstract}

${ }^{1}$ Kanaqin General Hospital- Diyala - Iraq. 


\section{Introduction}

The burden of diseases all over the world, due to medical disorders is enormous with wide geographical variation. Reviewing of morbidity and mortality data periodically could show new trends and may provide information for the planning and evaluation of country's health care services [1].It is observed that the pattern of medical diseases in developed countries is different from that in the developing countries.

In studies performed in developed countries, medical admissions accounted for $22.2 \%$, $33.0 \%$, and $13.0 \%$ of total hospital admissions in U.S.A, Western Australia and Hong Kong, respectively [2,3].Whereas, in a South African study admissions to the medical wards constituted $40 \%$ of the total hospital admissions [4].In developed countries non-communicable diseases namely cardiovascular diseases are the major reasons for medical admissions, For instance, admissions to medical wards at a hospital in Hong Kong were most frequently associated with the cardiovascular system which made up $30.3 \%$ of all medical cases [4].However in regions of developing countries, the increasing urbanization of the population is changing the morbidity pattern of diseases [5]. It is becoming widely observed that noncommunicable or chronic diseases are also now the main causes of death and disability in low and middle income countries $[6,7,8]$.

Chronic diseases such as cardiovascular primarily heart disease, stroke, cancer and diabetes are the main cause of health problem worldwide [9, 10].However the developing countries are still suffering with the communicable diseases. Due to lack of awareness of sanitation, lack of good water supply and environment, infectious diseases are still the major issues .Infectious diseases are commonly known as a cause of hospital admission in developing countries [11].

Hospital records: A specific focal point for disease-specific health promotion and education are usually Referral hospitals [12]. Though review of records of referral hospital admissions may not indicate the actual prevalence of diseases in the community; it will provide a cues about the varying pattern of diseases affecting the community [13].

In this situation the accurate statistics in developing countries are deficient, as in developing countries the data of hospital admission are still lacking [14]. Mortality and morbidity statistics are an essential resources for research in any country. Unfortunately in developing countries there is a deficiency of such data [15].

Cost considerations:The costs of treatment also supplying an essential information for providing a guide to the healthcare policy, and are usually under-reported in clinical research. Cost data are typically present on an individual-patient level, to give a total cost per patient. The distribution of costs is generally highly skewed, reflecting high costs expended by some patients because of type of complicated medical problem, prolonged hospital stay, and range of specific investigation and intervention. Healthcare planners need information on the total hospital budget, and the arithmetic mean is the required summary measure. Median cost 
(often presented in cost research) can be explained as the cost for a typical patient, but does not provide information on total costs [16].

Seasonal pattern in chronic diseases occurrence: It has been hypothesized that the frequency of occurrence of chronic health conditions differs in relation to the seasonal variation, several studies have described a seasonal fluctuation in mortality and morbidity related to those health conditions, a wide array of medical conditions exhibits seasonal patterns in their occurrence.

\section{Patients and Methods}

A retrospective study was conducted on 26700 patients that being admitted to the medical wards of Sulaimani Teaching Hospital from 1st January to 31th December 2015.

Sulaimani Teaching Hospital (Shahid Dr.Hemin hospital) is a general referral hospital in the Centre of Sulaimani city with a total capacity of 250 beds and it consists of two separate units for men and women admissions, it includes a department of internal medicine and two subspecialty departments (Neurology and Rheumatology departments).The hospital receives patients from inside and outside Sulaimani city. All the patients were referred from medical emergency department and outpatient clinics in addition to the private clinics. The data were obtained from the patients medical records in the statistic unit of the hospital.

All the cases that have been recorded on the year 2015 and their ages were from 14 years old and above were included in the study. The variables involved in the study included age of the patients, sex, residency and final diagnosis, these variables were entered into a Microsoft Office Excel database programme.

Some of hospitalized patients have an associated co-morbidity (one, two or even more), so more than one diagnosis were present on the case sheet, therefore additional information were needed from the case sheets to determine the final diagnosis. It should be noted that patients with cardiac diseases, psychiatric diseases, hematological and malignant diseases were not recorded totally in statistic unit of Sulaimani General Teaching Hospital because patients with such diseases are usually admitted at the Cardiac Center, Psychiatric Center and Hiwa Hospital respectively, so most of such diseases were not included in the study.

\section{Statistical analysis}

Descriptive statistics (numbers and percentage) had been calculated for all variables, as well as analytical statistics was done to find the relationship between variables. Chi-square was used for calculation of $\mathrm{P}$ value. A p-value $<0.05$ was considered as significant.

\section{Results}

Sixty patients were operated upon by The present study included 26700 patients whom were admitted to medical wards of Sulaimani Teaching Hospital during the year 2015. The most common age group that had been admitted in medical ward was between 51-60 years (18.16\%), followed by 61-7o years $(17.52 \%)$, while the least age group was 
between 14-20 years $(6.67 \%)$, this difference population $(\mathrm{M} \pm \mathrm{SD})$ was $51.03 \pm 19.58$ in age groups was statistically significant (p- years with a range of $14-120$ years, as value $=0.00)$. The mean age of the study shown in Table(1).

Table (1): Summerization of hospitalized patients by age group.

\begin{tabular}{|r|c||c||}
\hline Age group(year) & Number & Percentage(\%) \\
\hline \hline 20 & 1780 & 6.67 \\
\hline \hline $21-30$ & 3568 & 13.36 \\
\hline \hline $41-40$ & 3414 & 12.79 \\
\hline $51-60$ & 3984 & 14.92 \\
\hline $61-70$ & 4678 & 18.16 \\
\hline$\geq 71$ & 4428 & 16.58 \\
\hline \hline Total & 26700 & 100 \\
\hline \hline
\end{tabular}

\section{Gender distribution of the cases}

Of the 26700 patients, 11847 (44.38\%) were males and $14853(55.62 \%)$ were females with a significant difference in the number of males and females admitted to the medical ward ( $p$-value $=0.000)$ as shown in Figure (1).

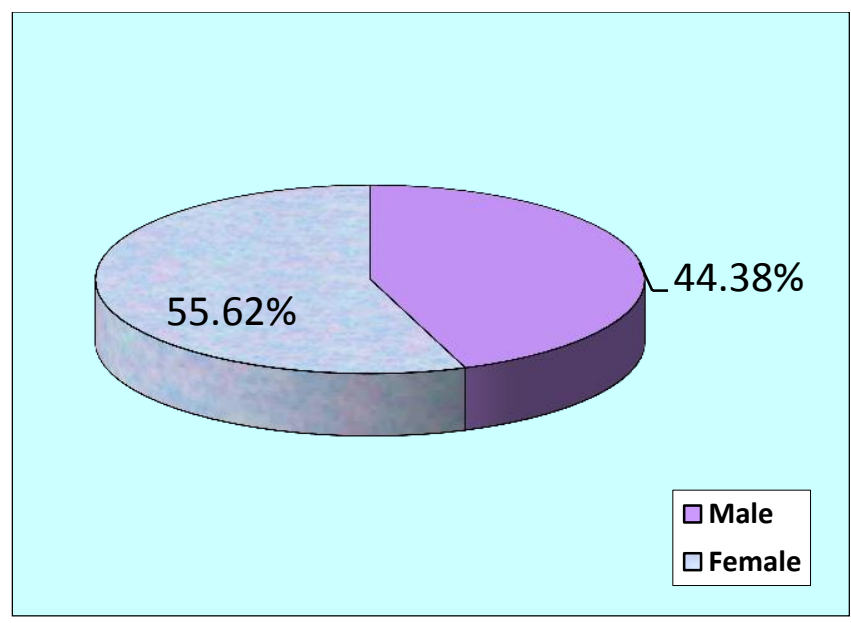

Figure (1): Distribution of hospitalized patients by Gender. 


\section{Residency}

The results revealed $16782(62.85 \%)$ of the areas and this difference is statistically patients were from the urban areas, significant (p-value $=0.000$ ) as shown in whereas9918 (37.15\%) were from the rural Figure( 2).

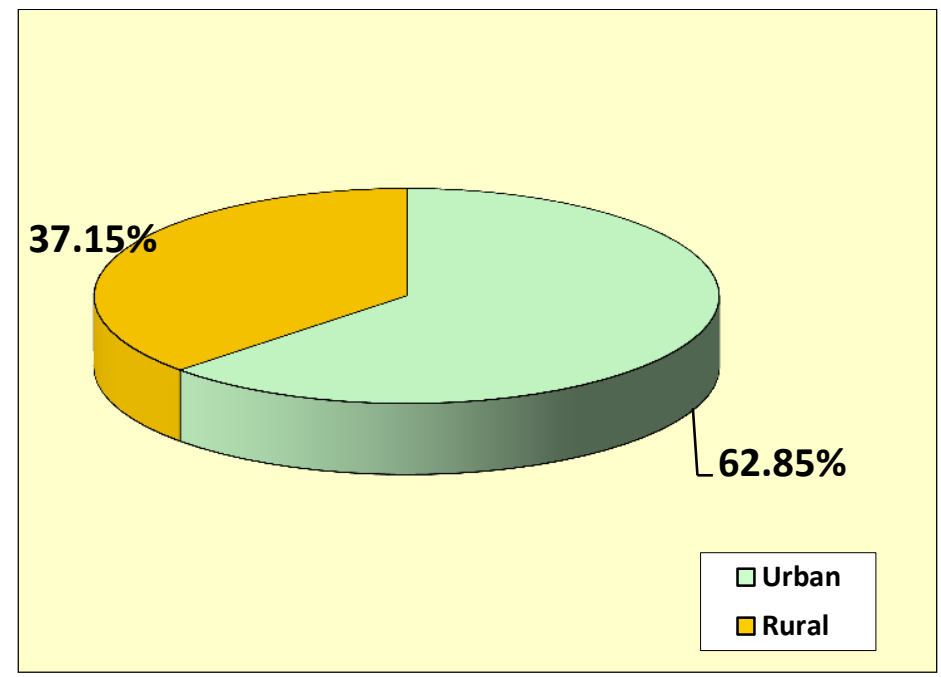

Figure (2): Distribution of hospitalized patients by Residency.

The most common patients that had been admitted to the medical wards had Gastroenteritis $(6.45 \%)$ followed by CVA (6.27\%) and COPD (5.52\%), while (26.04\%) of cases were not diagnosed (either they were discharged on their responsibility or there is no diagnosis on the case sheets). The results also revealed that there is a statistically significant difference in the frequency of disease occurrence among the males and females patients ( $p$-value $=0.000)$ as shown in Table(2). 
Table (2): Frequency distribution of the most common diseases.

\begin{tabular}{||l||c||c||c||}
\hline Diagnosis & $\begin{array}{c}\text { Male } \\
\text { No. (\%) }\end{array}$ & $\begin{array}{c}\text { Female } \\
\text { No. (\%) }\end{array}$ & Total \\
& $627(2.35)$ & $1094(4.10)$ & $1721(6.45)$ \\
\hline \hline Gastroenteritis & $882(3.30)$ & $793(2.97)$ & $1675(6.27)$ \\
\hline \hline COPD & $672(2.52)$ & $801(3)$ & $1473(5.52)$ \\
\hline \hline HT & $372(1.39)$ & $764(2.86)$ & $1136(4.25)$ \\
\hline \hline DM & $380(1.41)$ & $752(2.82)$ & $1132(4.23)$ \\
\hline \hline Bronchial asthma & $213(0.80)$ & $535(2)$ & $748(2.80)$ \\
\hline Heart failure & $367(1.37)$ & $329(1.23)$ & $696(2.60)$ \\
\hline Pneumonia & $279(1.05)$ & $329(1.23)$ & $608(2.28)$ \\
\hline \hline UTI & $168(0.63)$ & $344(1.29)$ & $512(1.92)$ \\
\hline \hline Anemia & $179(0.67$ & $317(1.19)$ & $496(1.86)$ \\
\hline \hline Miscellaneous diseases & $4212(15.79)$ & $5339(19.99)$ & $9551(35.78)$ \\
\hline \hline No diagnosis & $3496(13.10)$ & $3456(12.94)$ & $6952(26.04)$ \\
\hline \hline Total & $11847(44.38)$ & $14853(55.62)$ & $26700(100)$ \\
\hline \hline
\end{tabular}

The results of the study illustrate that the compared to the non-communicable diseases communicable diseases comprised $(27.86 \%)$ comprising $(72.14 \%)$ for common medical for the common medical diseases that had diseases, and this is statistically significant been admitted to the medicals wards ( $\mathrm{p}$-value $=0.00)$ as shown in Table(3).

Table (3): Percentage of the communicable and non-communicable diseases among the most common medical diseases.

\begin{tabular}{||l||c|c||}
\hline \hline Diseases & Number & Percentage (\%) \\
\hline \hline Communicable & 2841 & 27.86 \\
\hline \hline Non-communicable & 7356 & 72.14 \\
\hline \hline Total & 10197 & 100 \\
\hline
\end{tabular}




\section{Pattern of admission according to the} months of the year

The results demonstrated that the admissions also varied by months and seasons, the highest number of admissions was in July, comprising $(9.42 \%)$ of all admissions compared to the lowest in February which comprised (7.32\%) of all admissions, and this is statistically significant (p-value $=0.000$ ) as shown in table (4). In relation to seasons, the highest admissions were in Summer (June, July and August) comprising $(26.96 \%)$ of all admissions compared to the lowest in Winter (December ,January and February) comprising (23.60\%) of all admissions, with ( $\mathrm{p}$-value $=0.00)$ as shown inTable(5).

Table (4): Frequency of hospitalized patients according to the months of the year.

\begin{tabular}{|c|c||c||}
\hline Month & Number & Percentage (\%) \\
\hline \hline January & 2128 & 7.97 \\
\hline \hline February & 1956 & 7.32 \\
\hline \hline March & 2073 & 7.76 \\
\hline \hline April & 2176 & 8.15 \\
\hline \hline May & 2251 & 8.43 \\
\hline \hline June & 2367 & 8.87 \\
\hline \hline July & 2516 & 9.42 \\
\hline August & 2317 & 8.68 \\
\hline \hline September & 2231 & 8.36 \\
\hline \hline October & 2327 & 8.72 \\
\hline \hline November & 2142 & 8.02 \\
\hline \hline December & 2216 & 8.30 \\
\hline \hline Total & 26700 & 100 \\
\hline \hline
\end{tabular}

Table (5): Frequency of admissions according to the seasons.

\begin{tabular}{|c||c|c|}
\hline Season & Number & Percentage (\%) \\
\hline \hline Spring & 6500 & 24.34 \\
\hline \hline Summer & 7200 & 26.96 \\
\hline \hline Autumn & 6700 & 25.10 \\
\hline \hline Winter & 6300 & 23.60 \\
\hline \hline Total & 26700 & 100 \\
\hline
\end{tabular}




\section{Seasonal variations of the most common diseases}

The results also shows that there is a seasonal variation among the medical diseases admitted to the medical wards, season while CVA is more common in Winter season, also COPD, HT and DM showed a higher frequency of occurrence in winter season $(p-$ value $=0.00)$ as shown in Table (6).

Gastroenteritis is more common in Summer

Table (6): Seasonal variations of the most common medical diseases.

\begin{tabular}{||l||c||c||c||c||}
\hline \hline Diseases & $\begin{array}{c}\text { Spring } \\
\text { No. }(\%)\end{array}$ & $\begin{array}{c}\text { Summer } \\
\text { No. (\%) }\end{array}$ & $\begin{array}{c}\text { Autumn } \\
\text { No. (\%) }\end{array}$ & $\begin{array}{c}\text { Winter } \\
\text { No. (\%) }\end{array}$ \\
\hline \hline $\begin{array}{l}\text { Gastro- } \\
\text { enteritis }\end{array}$ & $\begin{array}{c}348 \\
(20.32)\end{array}$ & $\begin{array}{c}614 \\
(35.70)\end{array}$ & $\begin{array}{c}442 \\
(25.68)\end{array}$ & $\begin{array}{c}315 \\
(18.30)\end{array}$ \\
\hline \hline CVA & $\begin{array}{c}406 \\
(24.24)\end{array}$ & $\begin{array}{c}386 \\
(23.04)\end{array}$ & $\begin{array}{c}441 \\
(26.33)\end{array}$ & $\begin{array}{c}442 \\
(26.39)\end{array}$ \\
\hline \hline COPD & $\begin{array}{c}391 \\
(26.54)\end{array}$ & $\begin{array}{c}341 \\
(23.15)\end{array}$ & $\begin{array}{c}313 \\
(21.25)\end{array}$ & $\begin{array}{c}428 \\
(29.06)\end{array}$ \\
\hline \hline HT & $\begin{array}{c}294 \\
(25.88)\end{array}$ & $\begin{array}{c}240 \\
(21.13)\end{array}$ & $\begin{array}{c}295 \\
(25.97)\end{array}$ & $\begin{array}{c}307 \\
(27.02)\end{array}$ \\
\hline \hline DM & $\begin{array}{c}268 \\
(23.68)\end{array}$ & $\begin{array}{c}284 \\
(25.09)\end{array}$ & $\begin{array}{c}256 \\
(22.61)\end{array}$ & $\begin{array}{c}324 \\
(28.62)\end{array}$ \\
\hline
\end{tabular}

\section{Discussion}

This study information about the admissions was taken from the medical records of the patients in the statistic unit of the hospital. The most common age groups being admitted to the hospital were between (51-60 years and 61-70 years), these findings are agree with findings in a study that had been done in Nepal [17]. However these findings are disagree with findings of a study in Southwest Ethiopia which showed that the most frequent age of admission were between 21 to 30years [18], this could be identified by the variability in the population constitution of these countries.

The study also shows that the numbers of admissions were more common in females than in males and this is in agreement with a

study in Kurdistan region/ Iraq, this could be explained by either the fact that mortality is more common in males [19], or morbidity is more common in females as the two main causes for death are cardiovascular disease and stroke are more common in males leading to increased death rate in males while the less fatal conditions are usually found in females with increased frequency of admission to the hospitals and consequently more number of admission to the hospitals, also it could be explained by the fact that the females have a health care seeking behavior more than the males. This study the results of admissions from urban areas were more than that in the rural areas, it could be the presence of other general hospitals in the 
rural areas resulting in reduction of the number of referral cases admitted to the Sulaimani General Teaching Hospital.

The results have illustrated that chronic non-communicable diseases such as cerebrovascular accidents, hypertension and diabetes mellitus accounted for a significant portion of the medical admission profile and this is in agreement with similar studies in Nigeria which have also documented the emergence of non-communicable diseases over the last decade [20-24].

This study highlights the fact that communicable diseases are still represent a significant reason for admission to the medical wards at Sulaimani Teaching Hospital and this is similar to study done in medical wards of Kathmandu University Hospital, Nepal [25], this might be due to poor hygiene and poor sanitation, low socio economic condition in addition to increased amount of tobacco consumption and air pollution.

This study showed a variation in the number of admissions according to the seasons, the highest number were in Summer and the lowest number were in Winter, the cause of this may be actual difference in the pattern of diseases admitted to the medical wards. The results in this study revealed that there is a seasonal variation regarding the frequency of admission for the diseases to the medical wards, gastroenteritis cases were more common in summer and it could be that the causative agents to the gastroenteritis disease are in favoring the hot weather. CVA diseases were more common in the winter season [26], COPD is also more common in winter season and it could be due to a more frequent chest infection leading to more frequent admissions. The complicated hypertension is more common in winter and it could be due to its more frequent sequel like CVA and cardiac diseases which are more common in the winter season than in other seasons.

\section{Conclusion}

1- The most common age group for medical admission were at 51-60 year.

2- The frequency of admission were more common in females than in males. $\mathrm{T}$

3- he admission rate is more common in summer than in winter.

4- There is a seasonal variation in the occurrence of diseases.

5- The non-communicable diseases represent the main causes for medical admission than the communicable diseases.

\section{Recommendations}

1- Paying more attention to disease documentation and their diagnosis and depending on international classification of diseases (ICD) in writing of diagnosis.

2- Promotion of preventive programmes for both communicable and noncommunicable diseases.

3- Further studies are needed for studying the pattern of disease admission in other specialized hospitals to get more comprehensive pictures about the diseases in the community necessary for planning and resource allocation. 
4- There is a need for appropriate geriatric care for the population as high numbers of patients are in the old age group.

\section{References}

[1]Chijioke A and Kolo PM , Mortality Pattern at the adult medical wards of a Teaching hospital in Sub-Sahran Africa, Int. J. Trop. Med.2009,4 (1): 27-31.

[2]Cordle F, Tyroler HA. The use of Hospital medical records for epidemiologic research . 1. Differences in Hospital Utilization and in hospital mortality by agerace-sex- place of residence and socioeconomic status in a defined community population. Medical care.1974; 12: 596-610.

[3]Pan JC, cheung TD, Chau Y.N. Hospital, medical and cardiovascular disease admissions in a Hong Kong Hospital. Bulletin Hong Kong Medical Association . 1982; 34: 55-62.

[4]Marszalek J, De illiers PJ. Morbidity Profile of admissions to GF Jooste Hospital, Manenberg, Cape Town . SA Fam Pract. 2006; 48(6): 15-15e.

[5]Mudiayi TK, Onyanga- Omara A, Gelman ML. Trends of morbidity in general medicine at United Bulawayo Hospital, Bulawayo, Zimbabwe. The central African Journal of medicine. 1997; 43(8): 213-8.

[6]Miranda JJ, Patel V. Achieving the Millennium Development Goals: Does Mental Health play a Role? Plos Medicine. 2005; 2(10): e291.

[7] Perel P, Casas JP, Ortiz Z, Miranda JJ, Non communicable diseases and injuries in
Latin America and the Caribbean. Time for Action . Plos Medicane. 2006; 3(9): 344.

[8]World Health Organization. Preventing Chronic Diseases: A vital investment. WHO Global Report. Geneva: World Health Organization, 2005.

[9]Kardas, E. Ratajczyk-Pakalska. Reasons for elderly patient's hospitalization in department of internal medicine in Lodz . Aging Clin Exp Res. 2003 :15(1): 25.

[10]Respiratory Diseases in Canada. Canadian institute for health information . canidian lung association. Health Canada . Statics Canada . Ottawa .Canada. September 2001:1-102.

[11]World Health Organization. WHO Report on Tuberculosis Epidemics. Geneva: WHO1997.

[12]Hensher M, Price M, Adomakoh S. Referral Hospitals. In: Jamison DT, Breman JG, Measham AR editors. Disease control priorities in developing countries. New York: Oxford University Press; 2006. P. 1229.

[13]Ali E, Woldie M, reasons and outcomes of admissions to the medical wards of Jimma University Specialized Hospital, Southest Ethiopia, Ethiop J Health Sci.2010, Vol. 20, No.2, P 113-120.

[14]Pokharel BR , Humagain S, Pant P, Gurung R, Koju R, Bedi T.R.S; Spectrum of diseases in a medical ward of a teaching hospital in developing country a Journal of College of Medical Sciences-Nepal, 2012, Vol-8, No-2,7-11, P 7-11.

[15]Marszalek $\mathrm{J}$ and De Villiers PJT. Morbidity Profile of Admissions to GF 
Jooste Hospital, Manenberg, Cape Town. SA Fam Pract 2006; 48: 15ae.Available on line at http://www.safpj.co.za/index. php/safpj/article/view Article/608 (Accessed on June 2013).

[16]Eck C, Pierre RB, Hambleton IR, Medical Paediatric Admission Patterns at the University Hospital of the West Indies: Issues for Future Planning, West Indian Med J 2006; 55 (5): 1, P 340-345.

[17]Pokharel B R , Humagain S, Pant P, Gurung R , Koju R , Bedi T.R.S. ;Spectrum of diseases in a medical ward of a teaching hospital in a developing country, Journal of College of Medical Sciences-Nepal, 2012, Vol-8, No-2,7-11

[18]A. Elias. Reasons and outcome of admissions, Ethiop J Health Sci. 2010.21(2).113-20.

[19]Mohammad MO,Othman N,Omer

SA.Trend in admission and mortality in medical wards in Sulaimani General Teaching Hospital ,Kurdistan Acadimician Journal(KAJ) 2007,5(1) part A(23-33).

[20]Sanya EO, Akande TM, Opadijo G, Olarinoye JK, Bojuwoye BJ. Pattern and outcome of medical admission of elderly patients seen at the university of Ilorin Teaching Hospital, Ilorin. Afr J Med Med. Sci. 2008, 37(4): 375-381

[21]Ogun SA, Adelowo OO. Familoni OB, Jaiyesimi AE, Fakoya EA .Pattern and outcome of medical admission at the Ogun State Unevirsty Teaching Hospital,Sagamu a three year review.West Afr J Med.2009 ;19(4)-304-308.
[22] Odenigbo CU, Ogujiofor OC. Pattern of medical admission at the Federal Medical Centre, Asaba - A Two Year Review. Nig J Clin Pract. 2009; 12 (4): 395-397.

[23] Ike SO. The Pattern of admission into the Medical Wards of the University of Nigeria Teaching Hospital, Enugu. Nig J Clin Pract. 2008; 11(3):185 -192.

[24] Ansa VO, Ekott JU, Bassey EO. Profile and outcome of Cardiovascular admissions at the University of Uyo Teaching Hospital,Uyo - A five year review. Niger J Clin Pract . 2008; 11(1):22-24.

[25] Ogbera AO, Chinenye S, Onyekwere A, Fasanmade O. Prognostic indices of diabetes mortality. Ethn Dis. 2007, 17.721-5. [26] Manfredini R, Gallerani M, Portaluppi F, Salmi R, Fersini C. Chronobiological patterns of onset of acute cerebrovascular disease. Thromb Res 1997, 88(6): 451-46. 